\title{
Intensive versus Usual Control of Hypertension in the Prevention of Cardiovascular and Renal Outcomes: A Cumulative Meta-Analysis of Randomized Controlled Trials
}

\author{
Li Li Ling Li \\ Department of Cardiology, The First Affiliated Hospital of Zhengzhou University, \\ Zhengzhou, China
}

\section{Keywords}

Intensive blood pressure $\cdot$ Cardiovascular outcome $\cdot$ Renal outcome $\cdot$ Hypertension

\begin{abstract}
Background/Aims: Previous studies have reported inconsistent results regarding the treatment effects of intensive blood pressure (IBP) control in the prevention of cardiovascular and renal outcomes. We conducted this cumulative meta-analysis to evaluate the treatment effects of IBP control on cardiovascular and renal outcomes. Methods: We systematically searched PubMed, EMBASE, and the Cochrane Library databases from the date of their inception to October 2017, to identify randomized controlled trials (RCTs). The relative risks (RRs) with corresponding $95 \%$ confidence intervals $(\mathrm{Cls})$ were used to evaluate the treatment effects of IBP control by using a random-effects model. Results: The final analysis included 20 RCTs involving 56,687 individuals. The summary RRs indicated that IBP control treatment significantly reduced the risk of major cardiovascular events (RR: $0.85 ; 95 \% \mathrm{Cl}: 0.77-0.94 ; p=0.001$ ), including myocardial infarction (RR: $0.87 ; 95 \% \mathrm{Cl}: 0.76-1.00 ; p=0.044$ ), stroke (RR: $0.77 ; 95 \%$ Cl: $0.66-0.89 ; p<0.001$ ), and albuminuria (RR: 0.90; 95\% Cl: 0.84-0.97; $p=0.007$ ). However, IBP control had no significant effect on heart failure (RR: $0.80 ; 95 \% \mathrm{Cl}: 0.62-1.03 ; p=0.077$ ), all-cause mortality (RR: $0.91 ; 95 \% \mathrm{Cl}$ : $0.81-1.02 ; p=0.112$ ), cardiac death (RR: $0.91 ; 95 \% \mathrm{Cl}$ : $0.75-1.12 ; p=0.390$ ), non-cardiac death (RR: $0.98 ; 95 \%$ Cl: $0.86-1.12 ; p=0.773$ ), end-stage renal disease (RR: $0.90 ; 95 \% \mathrm{Cl}: 0.77-1.06 ; p=0.203$ ), and retinopathy (RR: $0.81 ; 95 \%$ Cl: $0.66-1.00$; $p=0.052)$. Conclusion: The findings of this study suggest that IBP control plays a beneficial role in the prevention of some major cardiovascular events, including myocardial infarction, stroke, and albuminuria.




\section{Kidney \\ Blood Pressure \\ Research}

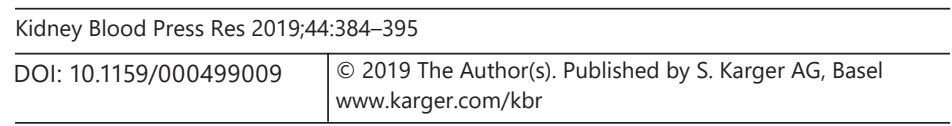

$\mathrm{Li}$ and Li: Hypertension in the Prevention of Cardiovascular and Renal Outcomes

\section{Introduction}

Cardiovascular disease (CVD) is the leading cause of morbidity and mortality worldwide and results in an overwhelming financial burden on healthcare systems [1,2]. Currently, in the USA, the treatment of CVD occupies nearly $1 / 6$ of the total healthcare budget $[3,4]$. High blood pressure (BP) is a leading risk factor for the development of CVD [5, 6], and evidence from previous studies indicates that a reduction in systolic blood pressure (SBP) could significantly reduce CVD risk [7, 8]. However, it is unclear whether a substantial BP reduction is correlated to greater improvement in CVD risk.

Numerous studies have suggested a target SBP of $<140 \mathrm{~mm} \mathrm{Hg}$ and a target diastolic BP (DBP) of $<90 \mathrm{~mm} \mathrm{Hg}$ for the management of hypertension in elderly hypertensive patients. Although, the benefit of further BP reduction in diabetes mellitus (DM) and kidney disease patients has already been demonstrated, the treatment effect of further BP reduction in patients with other disease status remains unclear [9-11]. Xie et al. conducted a meta-analysis to evaluate the treatment effect of intensive BP (IBP) control on the risk of major cardiovascular events (MACEs), myocardial infarction (MI), stroke, albuminuria, and retinopathy and compared it with the treatment effect of standard BP control [12]. However, additional new randomized controlled trials (RCTs) have already been completed, and these studies should be re-evaluated and updated with the pooled results. Therefore, we conducted a meta-analysis to evaluate the treatment effect of IBP control in reducing cardiovascular and renal outcomes and determined the evidence base for IBP control in clinical practice using a cumulative metaanalytic approach.

\section{Methods}

\section{Search Strategy and Inclusion Criteria}

The meta-analysis was performed according to the Preferred Reporting Items for Systematic Reviews and Meta-Analysis statement [13]. RCTs that investigated the treatment effect of IBP control on cardiovascular and renal outcomes and were published in English were included in this study, regardless of the publication status. Outcomes including MACEs, MI, stroke, heart failure, all-cause mortality, cardiac death, non-cardiac death, end-stage renal disease (ESRD), retinopathy, and albuminuria were analyzed. PubMed, EMBASE, and the Cochrane Library databases were searched for studies from the time of database inception to October 2017, and the following core search terms were used: "target blood pressure" OR "intensive blood pressure treatment" OR "intensive blood pressure control" OR "strict blood pressure treatment" OR "strict blood pressure control" OR "tight blood pressure treatment" OR "tight blood pressure control" AND "randomized controlled trials." We also conducted manual searches of reference lists from potentially relevant studies to identify additional eligible studies.

The literature search and study selection process were independently conducted by two authors, and any inconsistency was resolved by group discussion until a consensus was reached. Study inclusion criteria were as follows: (1) the study had to have a randomized controlled design; (2) the study investigated the treatment effect of IBP control compared with standard BP control; (3) the duration of follow-up period was greater than one year; and (4) the study reported at least 1 of following outcomes: MACEs, MI, stroke, heart failure, allcause mortality, cardiac death, non-cardiac death, ESRD, retinopathy, or albuminuria. We excluded all observational studies due to confounding variables or bias. 


\section{Kidney \\ Blood Pressure \\ Research}

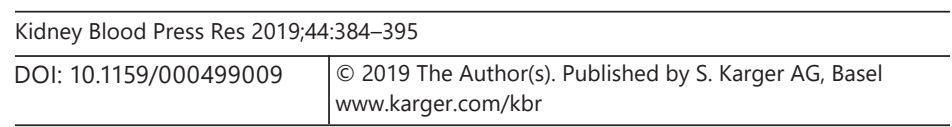

$\mathrm{Li}$ and Li: Hypertension in the Prevention of Cardiovascular and Renal Outcomes

\section{Data Collection and Quality Assessment}

Data extraction and quality assessment were conducted independently by two authors. Information was examined and adjudicated by an additional author to refer the original studies. The data abstracted included the first author or study group's name, publication year, country, sample size, mean age, percentage male, body mass index (BMI), baseline SBP, baseline DBP, BP achieved in IBP group, BP achieved in control group, difference in BP reduction, glomerular filtration rate, serum creatinine, disease status, target BP control, MACE definitions, percentage of smokers, and follow-up duration. In addition, the investigated outcome variables was abstracted including MACEs, MI, stroke, heart failure, all-cause mortality, cardiac death, non-cardiac death, ESRD, retinopathy, and albuminuria. The JADAD scale was employed to evaluate methodological quality, which has been validated by evaluating the quality of RCT in meta-analyses [14]. The JADAD was based on randomization (1 or 0 ), concealment of the treatment allocation ( 1 or 0 ), blinding ( 1 or 0 ), completeness of followup ( 1 or 0$)$, and the use of intention-to-treat analysis with a total of 5 scores developed for assessment.

\section{Statistical Analysis}

We assigned the results from each study as dichotomous frequency data or effect estimates and corresponding 95\% CIs. The fixed-effect model was first used to calculate the summary RR and 95\% CI for the treatment effect of IBP control on MACEs, MI, stroke, heart failure, all-cause mortality, cardiac death, non-cardiac death, ESRD, retinopathy, and albuminuria [15]. We then combined the RRs of cardiovascular or renal outcomes in IBP control to usual BP control means by using a random-effects model due to the true underlying effect variability among the included trials [16]. The cumulative meta-analysis for MACEs, MI, stroke, heart failure, all-cause mortality, cardiac death, non-cardiac death, ESRD, retinopathy, and albuminuria were conducted sequentially according to the year in which they first published. Heterogeneity among the included studies was investigated using I-square and Q statistic, and a $p$ value $<0.10$ was considered significant heterogeneity $[17,18]$. Sensitivity analyses were conducted by removing each study from the overall analysis [19]. Stratified analyses were conducted for MACEs and ESRD based on publication year, sample size, mean age, male inclusion percentage, BMI, the difference in SBP reduction, disease status, the smoker inclusion percentage, follow-up duration, and study quality. Funnel plot, Egger [20], and Begg [21] tests were used to evaluate publication bias for MACEs and ESRD. $p$ values were two-sided, and if they were $<0.05$, they were considered statistically significant across the included studies. Statistical analyses were conducted using STATA software (version 10.0; Stata Corporation, College Station, TX, USA).

\section{Results}

\section{Search of the Published Literature}

A total of 597 studies were identified from our electronic search, of which 536 were excluded due to duplication, irrelevance, and issues related to study design. We retrieved the full text for the remaining 61 studies, and 20 RCTs (22 studies) were selected for the final analysis after detailed evaluations [12, 22-42]. The manual search of the reference lists of relevant reviews yielded no new eligible studies. The results of the study selection process are shown in Figure 1, and the general characteristics of the included studies are presented in Table 1 and online supplement 1 (see www.karger.com/doi/10.1159/000499009 for all online suppl. material). 


\section{Kidney \\ Blood Pressure \\ Research}

Fig. 1. Flow diagram of the literature search and trials selection process.

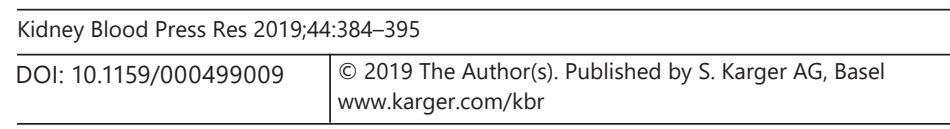

Li and Li: Hypertension in the Prevention of Cardiovascular and Renal Outcomes

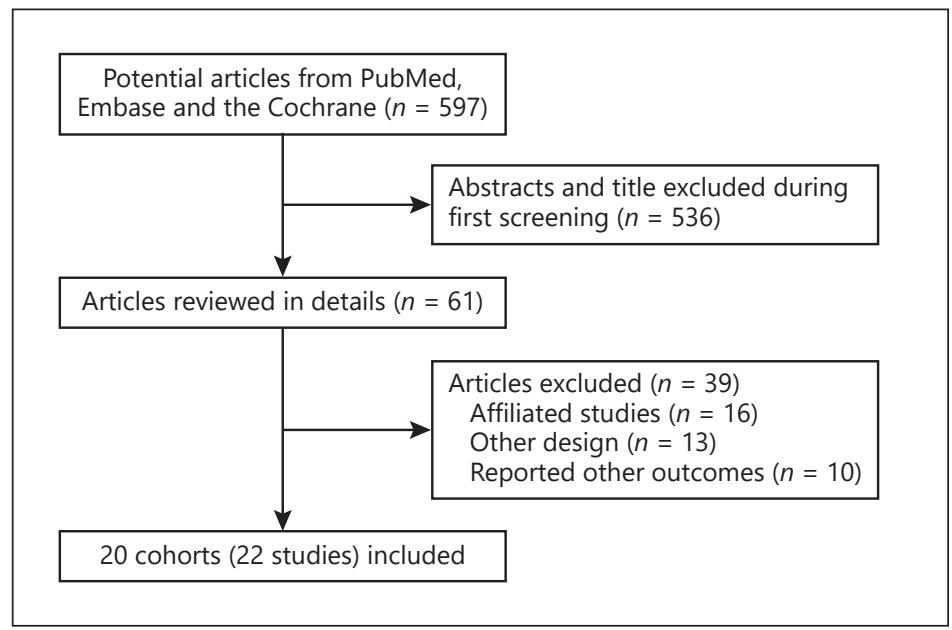

\section{Study Characteristics}

Twenty RCTs involving 56,687 subjects were included in the final meta-analysis. The follow-up duration ranged from 1 to 10 years, whereas the number of subjects in an individual trial ranged from 75 to 18,790. Eight trials were conducted in the USA or Canada, five in Europe, five in Asia, and the remaining two in multiple countries. Four of the trials included in the final meta-analysis reported patients with type $2 \mathrm{DM}$, whereas the remaining reported patients without type $2 \mathrm{DM}$. The mean baseline SBP of subjects in the included trials ranged from $123.0 \mathrm{~mm} \mathrm{Hg}$ to $171.6 \mathrm{~mm} \mathrm{Hg}$, and mean baseline DBP ranged from $76.0 \mathrm{~mm} \mathrm{Hg}$ to 105.0 $\mathrm{mm} \mathrm{Hg}$. Study quality was evaluated by a JADAD scale, and a study with a score of 4 or higher was regarded as a high-quality study. Overall, 10 trials had a score of 4, and the remaining 10 had a score of 3.

\section{Major Cardiovascular Events}

A total of 15 trials reported a treatment effect of IBP control on the risk of MACEs. The summary RR indicated that relative to the standard BP control strategy, IBP control significantly reduced the risk of MACEs (RR: 0.85; 95\% CI: 0.77-0.94; $p=0.001$; online supplement $2-$ Fig. $\mathrm{S} 1)$, and unimportant heterogeneity across the included trials was observed $\left(I^{2}=28.1 \%\right.$; $p=$ $0.141)$. Consequently, a sensitivity analysis was conducted, and the conclusion was not affected by the sequential exclusion of individual studies from the overall analysis (online supplement 3 - Table S1). Although there was a significant treatment effect of IBP control for the prevention MACEs in multiple subsets, we noted that IBP control has no significant impact on MACEs when the sample size was $<1,000$, the mean age of the included subjects was $<60.0$ years, the percentage of male $\geq 60.0 \%$, BMI $\geq 30.0 \mathrm{~kg} / \mathrm{m}^{2}$, difference in SBP reduction $<5.0 \mathrm{~mm} \mathrm{Hg}$, the percentage of smokers included was $<20.0 \%$, follow-up duration $\geq 5$ years, and all included studies were high quality (Table 2). The findings of cumulative meta-analysis indicated a significant treatment effect for IBP control on MACEs by accumulative the trial to 2005 (Fig. 2A).

\section{Myocardial Infarction}

A total of 12 studies reported a treatment effect of IBP control on the risk of developing an MI. We noted that IBP control was associated with a reduced risk of MI as compared with standard BP control (RR: 0.87; 95\% CI: 0.76-1.00; $p=0.044$; with no evidence of heterogeneity; online supplement 2 - Fig. S2). The conclusion was variable after sequential exclusion of individual studies due to marginal significant effect (online supplement 3 - Table S2). The 
Li and Li: Hypertension in the Prevention of Cardiovascular and Renal Outcomes

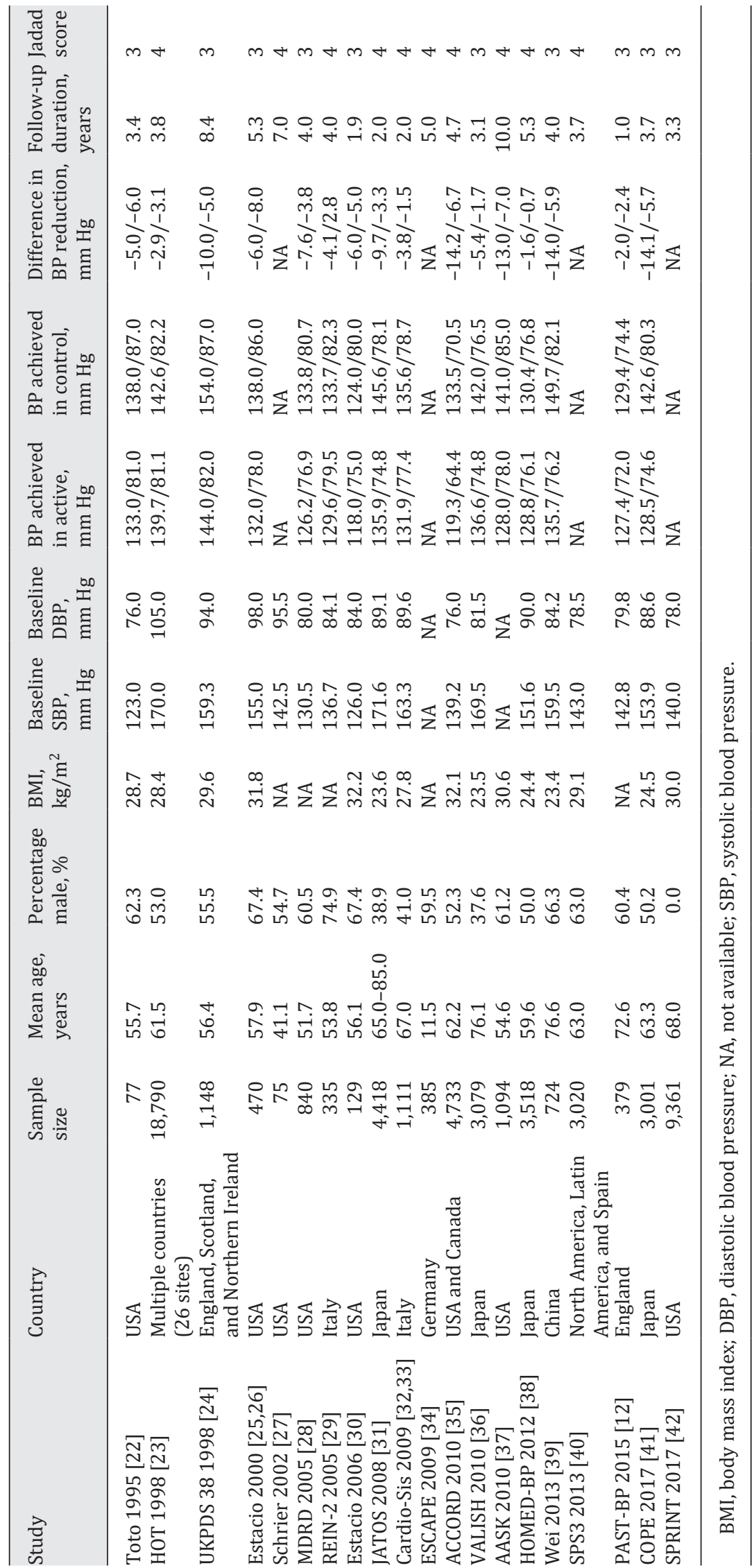


Table 2. Subgroup analysis for major cardiovascular events and end-stage renal disease

\begin{tabular}{|c|c|c|c|c|c|c|c|}
\hline Outcomes & Factor & Subgroup & RR and 95\% CI & $p$ value & $\begin{array}{l}\text { Hetero- } \\
\text { geneity, \% }\end{array}$ & $p$ value & $\begin{array}{l}p \text { value } \\
\text { between } \\
\text { subgroups }\end{array}$ \\
\hline \multirow[t]{10}{*}{$\begin{array}{l}\text { Major cardio- } \\
\text { vascular events }\end{array}$} & Publication year & $\begin{array}{l}2010 \text { or after } \\
\text { Before } 2010\end{array}$ & $\begin{array}{l}0.85(0.74-0.98) \\
0.85(0.73-0.99)\end{array}$ & $\begin{array}{l}0.029 \\
0.033\end{array}$ & $\begin{array}{l}39.3 \\
24.9\end{array}$ & $\begin{array}{l}0.117 \\
0.230\end{array}$ & 0.905 \\
\hline & Sample size & $\begin{array}{l}\geq 1,000 \\
<1,000\end{array}$ & $\begin{array}{l}0.87(0.78-0.97) \\
0.78(0.61-1.01)\end{array}$ & $\begin{array}{l}0.009 \\
0.061\end{array}$ & $\begin{array}{l}36.5 \\
13.2\end{array}$ & $\begin{array}{l}0.116 \\
0.330\end{array}$ & 0.333 \\
\hline & Mean age, years & $\begin{array}{l}\geq 60.0 \\
<60.0\end{array}$ & $\begin{array}{l}0.83(0.73-0.94) \\
0.90(0.75-1.09)\end{array}$ & $\begin{array}{l}0.003 \\
0.287\end{array}$ & $\begin{array}{l}33.8 \\
30.2\end{array}$ & $\begin{array}{l}0.147 \\
0.198\end{array}$ & 0.665 \\
\hline & Percentage male, \% & $\begin{array}{l}\geq 60.0 \\
<60.0\end{array}$ & $\begin{array}{l}0.88(0.73-1.04) \\
0.84(0.74-0.95)\end{array}$ & $\begin{array}{l}0.140 \\
0.005\end{array}$ & $\begin{array}{l}30.6 \\
33.0\end{array}$ & $\begin{array}{l}0.184 \\
0.165\end{array}$ & 0.559 \\
\hline & BMI, $\mathrm{kg} / \mathrm{m}^{2}$ & $\begin{array}{l}\geq 30.0 \\
<30.0\end{array}$ & $\begin{array}{l}0.95(0.84-1.08) \\
0.80(0.70-0.92)\end{array}$ & $\begin{array}{l}0.421 \\
0.001\end{array}$ & $\begin{array}{r}0.0 \\
41.9\end{array}$ & $\begin{array}{l}0.682 \\
0.088\end{array}$ & 0.155 \\
\hline & $\begin{array}{l}\text { Difference in } \mathrm{SBP} \\
\text { reduction, } \mathrm{mm} \mathrm{Hg}\end{array}$ & $\begin{array}{l}\geq 5.0 \\
<5.0\end{array}$ & $\begin{array}{l}0.85(0.74-0.97) \\
0.83(0.62-1.10)\end{array}$ & $\begin{array}{l}0.017 \\
0.199\end{array}$ & $\begin{array}{l}39.7 \\
28.2\end{array}$ & $\begin{array}{l}0.093 \\
0.233\end{array}$ & 0.833 \\
\hline & Disease status & $\begin{array}{l}\text { Type } 2 \text { DM } \\
\text { Without type } 2 \text { DM }\end{array}$ & $\begin{array}{l}0.83(0.73-0.94) \\
0.86(0.75-0.98)\end{array}$ & $\begin{array}{l}0.004 \\
0.026\end{array}$ & $\begin{array}{r}3.7 \\
37.6\end{array}$ & $\begin{array}{l}0.386 \\
0.099\end{array}$ & 0.402 \\
\hline & $\begin{array}{l}\text { Percentage of } \\
\text { smoker, } \%\end{array}$ & $\begin{array}{l}\geq 20.0 \\
<20.0\end{array}$ & $\begin{array}{l}0.78(0.65-0.94) \\
0.92(0.82-1.02)\end{array}$ & $\begin{array}{l}0.009 \\
0.121\end{array}$ & $\begin{array}{r}59.9 \\
0.0\end{array}$ & $\begin{array}{l}0.021 \\
0.902\end{array}$ & 0.233 \\
\hline & $\begin{array}{l}\text { Follow-up duration, } \\
\text { years }\end{array}$ & $\begin{array}{l}\geq 5.0 \\
<5.0\end{array}$ & $\begin{array}{l}0.91(0.73-1.12) \\
0.84(0.75-0.94)\end{array}$ & $\begin{array}{l}0.373 \\
0.002\end{array}$ & $\begin{array}{l}51.7 \\
19.5\end{array}$ & $\begin{array}{l}0.082 \\
0.257\end{array}$ & 0.691 \\
\hline & Study quality & $\begin{array}{l}\text { High } \\
\text { Low }\end{array}$ & $\begin{array}{l}0.92(0.84-1.00) \\
0.74(0.64-0.85)\end{array}$ & $\begin{array}{r}0.057 \\
<0.001\end{array}$ & $\begin{array}{l}0.1 \\
0.0\end{array}$ & $\begin{array}{l}0.428 \\
0.438\end{array}$ & 0.008 \\
\hline \multirow[t]{10}{*}{$\begin{array}{l}\text { End-stage renal } \\
\text { disease }\end{array}$} & Publication year & $\begin{array}{l}2010 \text { or after } \\
\text { Before } 2010\end{array}$ & $\begin{array}{l}0.90(0.70-1.15) \\
0.90(0.73-1.11)\end{array}$ & $\begin{array}{l}0.395 \\
0.342\end{array}$ & $\begin{array}{l}0.0 \\
0.0\end{array}$ & $\begin{array}{l}0.323 \\
0.435\end{array}$ & 0.962 \\
\hline & Sample size & $\begin{array}{l}\geq 1,000 \\
<1,000\end{array}$ & $\begin{array}{l}0.88(0.69-1.11) \\
0.94(0.71-1.23)\end{array}$ & $\begin{array}{l}0.273 \\
0.635\end{array}$ & $\begin{array}{r}0.0 \\
22.9\end{array}$ & $\begin{array}{l}0.662 \\
0.269\end{array}$ & 0.754 \\
\hline & Mean age, years & $\begin{array}{l}\geq 60.0 \\
<60.0\end{array}$ & $\begin{array}{l}1.00(0.72-1.40) \\
0.87(0.72-1.06)\end{array}$ & $\begin{array}{l}0.987 \\
0.165\end{array}$ & $\begin{array}{l}0.0 \\
4.7\end{array}$ & $\begin{array}{l}0.793 \\
0.391\end{array}$ & 0.475 \\
\hline & Percentage male, \% & $\begin{array}{l}\geq 60.0 \\
<60.0\end{array}$ & $\begin{array}{l}0.93(0.73-1.19) \\
0.87(0.67-1.14)\end{array}$ & $\begin{array}{l}0.573 \\
0.313\end{array}$ & $\begin{array}{r}24.2 \\
0.0\end{array}$ & $\begin{array}{l}0.266 \\
0.586\end{array}$ & 0.775 \\
\hline & $\mathrm{BMI}, \mathrm{kg} / \mathrm{m}^{2}$ & $\begin{array}{l}\geq 30.0 \\
<30.0\end{array}$ & $\begin{array}{l}0.90(0.70-1.15) \\
0.99(0.45-2.18)\end{array}$ & $\begin{array}{l}0.395 \\
0.974\end{array}$ & $\begin{array}{r}0.0 \\
33.3\end{array}$ & $\begin{array}{l}0.323 \\
0.223\end{array}$ & 0.995 \\
\hline & $\begin{array}{l}\text { Difference in SBP } \\
\text { reduction, } \mathrm{mm} \mathrm{Hg}\end{array}$ & $\begin{array}{l}\geq 5.0 \\
<5.0\end{array}$ & $\begin{array}{l}0.89(0.74-1.08) \\
1.12(0.74-1.69)\end{array}$ & $\begin{array}{l}0.231 \\
0.591\end{array}$ & $\begin{array}{l}0.0 \\
-\end{array}$ & $\begin{array}{l}0.546 \\
-\end{array}$ & 0.391 \\
\hline & Disease status & $\begin{array}{l}\text { Type } 2 \text { DM } \\
\text { Without type } 2 \text { DM }\end{array}$ & $\begin{array}{l}0.96(0.68-1.35) \\
0.88(0.74-1.06)\end{array}$ & $\begin{array}{l}0.812 \\
0.187\end{array}$ & $\begin{array}{l}0.0 \\
0.0\end{array}$ & $\begin{array}{l}0.321 \\
0.456\end{array}$ & 0.675 \\
\hline & $\begin{array}{l}\text { Percentage of } \\
\text { smoker, } \%\end{array}$ & $\begin{array}{l}\geq 20.0 \\
<20.0\end{array}$ & $\begin{array}{l}0.77(0.55-1.07) \\
1.00(0.72-1.40)\end{array}$ & $\begin{array}{l}0.118 \\
0.987\end{array}$ & $\begin{array}{l}0.0 \\
0.0\end{array}$ & $\begin{array}{l}0.596 \\
0.793\end{array}$ & 0.512 \\
\hline & $\begin{array}{l}\text { Follow-up duration, } \\
\text { years }\end{array}$ & $\begin{array}{l}\geq 5.0 \\
<5.0\end{array}$ & $\begin{array}{l}0.75(0.57-0.99) \\
0.99(0.81-1.21)\end{array}$ & $\begin{array}{l}0.041 \\
0.944\end{array}$ & $\begin{array}{l}0.0 \\
0.0\end{array}$ & $\begin{array}{l}0.734 \\
0.554\end{array}$ & 0.109 \\
\hline & Study quality & $\begin{array}{l}\text { High } \\
\text { Low }\end{array}$ & $\begin{array}{l}0.91(0.75-1.10) \\
0.93(0.52-1.65)\end{array}$ & $\begin{array}{l}0.320 \\
0.792\end{array}$ & $\begin{array}{r}0.0 \\
34.2\end{array}$ & $\begin{array}{l}0.577 \\
0.219\end{array}$ & 0.880 \\
\hline
\end{tabular}




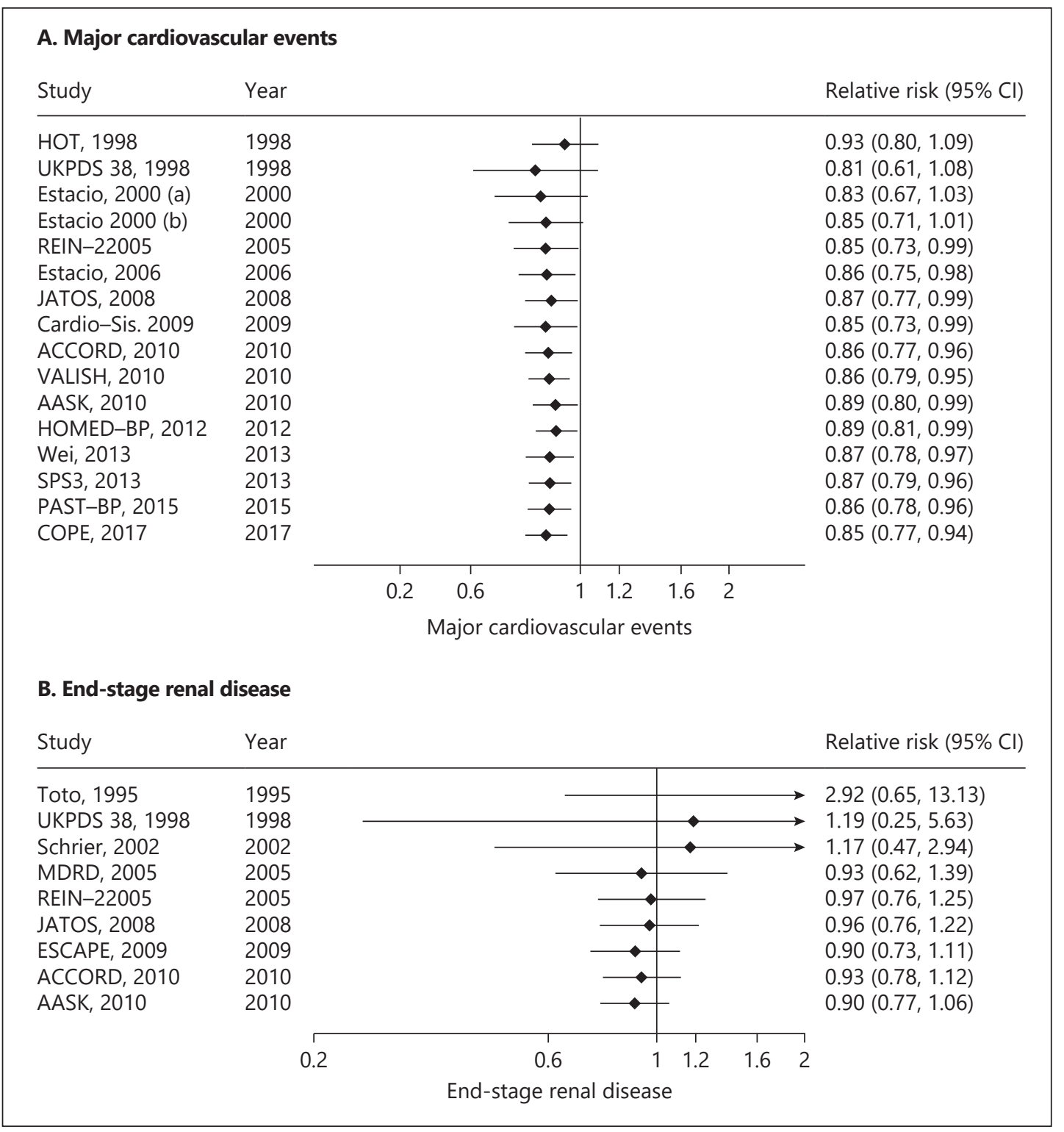

Fig. 2. Cumulative meta-analysis of the IBP control for major cardiovascular events (MACEs) (A) and endstage renal disease (ESRD) (B).

non-significant result persisted when cumulative trials published up to 2013 (online supplement 4 - Fig. S1).

\section{Stroke}

A total of 12 studies reported a treatment effect of IBP control on the risk of stroke. In the pooled analysis, IBP control showed a beneficial effect on stroke risk as compared with standard BP control (RR: 0.77; 95\% CI: 0.66-0.89; $p<0.001$; online supplement 2 - Fig. S3), and unimportant heterogeneity was detected $\left(I^{2}=20.6 \% ; p=0.229\right)$. The sensitivity analysis suggested that the conclusion was not affected by the exclusion of any specific study (online supplement 3 - Table S3). A significant treatment effect of IBP control for stroke was observed when accumulative the trial published by 2009 (online supplement 4 - Fig. S2). 


\section{Kidney \\ Blood Pressure \\ Research}

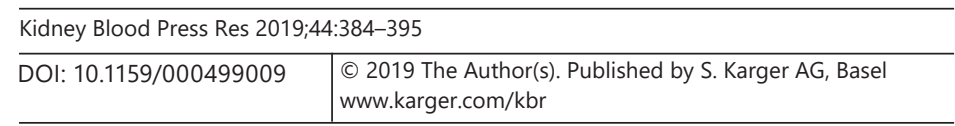

Li and Li: Hypertension in the Prevention of Cardiovascular and Renal Outcomes

\section{Heart Failure}

A total of 10 studies reported a treatment effect of IBP control on the risk of heart failure. There was no significant difference between IBP control and standard BP control on the risk of heart failure (RR: 0.80; 95\% CI: 0.62-1.03; $p=0.077$; online supplement 2 - Fig. S4). Substantial heterogeneity was detected among the included studies, and the results were changed after excluding the study conducted by the HOT or AASK group (online supplement 3 - Table S4). The non-significant result persisted when cumulative meta-analyses for heart failure online supplement 4 - Fig. S3).

\section{All-Cause Mortality}

A total of 19 studies reported a treatment effect of IBP control on the risk of all-cause mortality. We noted IBP control does not affect all-cause mortality as compared with standard BP control (RR: 0.91; 95\% CI: 0.81-1.02; $p=0.112$; online supplement 2 - Fig. S5). Unimportant heterogeneity was observed across included studies $\left(I^{2}=17.3 \% ; p=0.239\right)$. A sensitivity analysis was conducted and after excluding the trial conducted by the HOT group, which specifically included a large sample size and greater baseline BP. We noted IBP control significantly reduced the risk of all-cause mortality (RR: $0.88 ; 95 \%$ CI: $0.78-0.99 ; p=0.028$; online supplement 3 - Fig. S5). The non-significant result persisted when cumulative meta-analyses were performed for all-cause mortality (online supplement 4 - Fig. S4).

\section{Cardiac Death and Non-Cardiac Death}

Eleven RCTs reported a significant effect of IBP control on the risk of cardiac death and non-cardiac death, respectively. We noted that IBP control has no effect on cardiac death (RR: 0.91; 95\% CI: 0.75-1.12; $p=0.390$; with significant heterogeneity; online supplement 2 - Fig. S6), and non-cardiac death (RR: 0.98; 95\% CI: 0.86-1.12; $p=0.773$; with no evidence of heterogeneity; online supplement 2 - Fig. S7). The results of the sensitivity analysis were consistent with those of the overall analysis and are shown in online supplement 3 - Tables S6 and S7. Lack of statistical significance persisted when cumulative meta-analyses were conducted for cardiac death (online supplement 4 - Fig. S5) and non-cardiac death (online supplement 4 - Fig. S6).

\section{End-Stage Renal Disease}

A total of 9 studies reported a treatment effect of IBP control on the risk of ESRD. There was no significant difference between IBP control and standard BP control on ESRD risk (RR: 0.90; 95\% CI: 0.77-1.06; $p=0.203$; with no evidence of heterogeneity; online supplement 2 Fig. S8). Although each study was sequentially excluded from the pooled analysis, the conclusion was not affected by the exclusion of any specific study (online supplement 3 - Table S8). The non-significant result persisted when a cumulative meta-analysis for ESRD was performed (Fig. 2B). Subgroup analysis indicated IBP control significantly reduced the risk of ESRD if the duration of follow-up was $\geq 5$ years (RR: 0.75 ; 95\% CI: 0.57-0.99; $p=0.041$; Table 2).

\section{Retinopathy and Albuminuria}

Three RCTs reported a significant effect of IBP control on the risk of retinopathy and albuminuria, respectively. We noted that IBP control has no effect on the risk of retinopathy (RR: 0.81; 95\% CI: 0.66-1.00; $p=0.052$; with significant heterogeneity; online supplement 2 - Fig. S9), whereas it significantly reduced the risk of albuminuria (RR: 0.90; 95\% CI: 0.84$0.97 ; p=0.007$; with no evidence of heterogeneity; online supplement $2-$ Fig. S10). The sensitivity analysis indicated the results varied possibly due to the smaller number of included studies (online supplement 3 - Tables S9 and S10). The findings of cumulative meta-analyses indicated the results were altered and presented in online supplement 4 - Figs. S7 and S8. 


\section{Kidney \\ Blood Pressure \\ Research}

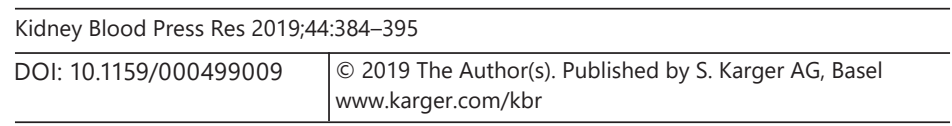

Li and Li: Hypertension in the Prevention of Cardiovascular and Renal Outcomes

\section{Publication Bias}

Review of the funnel plots could not rule out a publication bias for MACEs and ESRD (online supplement 5 - Fig. S1). Further, the Egger and Begg test results showed no evidence of publication bias for MACEs ( $p$ value for Egger: 0.379; $p$ value for Begg: 0.558) and ESRD ( $p$ value for Egger: 0.494; $p$ value for Begg: 0.466).

\section{Discussion}

Due to the characteristics of hypertension that impact the progression of cardiovascular and renal outcomes, the included RCTs evaluated the treatment effect of IBP control on cardiovascular and renal outcomes according to publication year, sample size, mean age, percentage male, BMI, difference in SBP reduction, disease status, percentage of smokers, follow-up duration, and took into consideration the quality of the investigation. The metaanalysis included 56,687 subjects from 20 RCTs with a broad range of individual characteristics. The findings of this study indicated that IBP control approaches significantly reduce the risk of MACEs, MI, stroke, and albuminuria. However, IBP control does not affect heart failure, all-cause mortality, cardiac death, non-cardiac death, ESRD, and retinopathy. Subgroup analysis suggests that long-term IBP control could play a beneficial role in the prevention of ESRD.

A previous meta-analysis based on 9 investigations in chronic kidney disease patients found that IBP control did not provide additional benefits for renal outcomes when compared with standard BP control during the follow-up period of 3.3 years, whereas this effect was not observed in diabetic patients [43]. However, the authors did not investigate the treatment effects of IBP control on cardiovascular outcomes. Further, Weiss et al. included 21 RCTs indicates IBP was associated with lower risk of all-cause mortality, MACEs, and stroke, whereas other specific outcomes were not evaluated [44]. Reboldi et al. conducted a meta-analysis in 31 studies and including 73,913 diabetic patients and indicated the protected effect of stroke was increases with the magnitude of BP reduction, whereas this effect was not observed for MI [45]. The results of previous investigations had inconsistent conclusions due to marginal significant results and the potential impact of the inclusion of additional studies. The major strengths of this study included the comprehensive inclusion of RCTs with large sample sizes and a broad selection of subjects. The large sample sizes ensured the stability of our conclusions, and the general characteristics of the subjects ensured the applicability of the summary results. Further, the treatment effects of IBP control for preventing MACEs and ESRD in specific characteristics of subjects were conducted.

The pooled results showed a significantly reduced risk of MACEs, MI, and stroke for IBP control when compared with standard BP control, but this did not impact the risk of heart failure, all-cause mortality, cardiac death, and non-cardiac death. Several previous investigations have suggested that IBP control achieves a clinically relevant reduction in the complications related to CVD. However, several reasons could affect the treatment effects of IBP control, including (1) the sensitivity of diagnosis of MACEs were different among the included trials [46]; (2) differing inclusion criteria and blindness to the analysis could have affected the clinical decisions; (3) the incidence of MACEs was different according to ethnicity; (4) disease status was associated with different risk level of included subjects; and (5) different baseline BP and target of BP reduction was introduced potential confounder factors. Subgroup analyses indicated the treatment effects of IBP was greater in subjects $>60.0$ years, the percentage of male $<60.0 \%$, BMI $<30.0 \mathrm{~kg} / \mathrm{m}^{2}$, the difference in SBP reduction $\geq 5.0 \mathrm{~mm} \mathrm{Hg}$, and the inclusion of $\geq 20.0 \%$ smokers. These findings suggest that IBP control plays a beneficial role in the development of MACEs in high-risk subjects. 
The results from this analysis suggest that IBP control is not associated with the progression of ESRD, but it might play a beneficial effect on retinopathy and albuminuria. These results were focused on DM and chronic kidney disease patients. Further, subgroup analysis indicated that IBP control is associated with lower risk of ESRD when the follow-up duration is $>5$ years. All the included trials reported herein showed no significant effect of IBP control on ESRD, the reason for this could be the incidence of ESRD being lower than expected, which was associated with lower statistical power and acquired broad 95\% CI. Finally, the summary results for retinopathy and albuminuria might be varied due to the few studies included and potential confounding factors that could be explored.

This meta-analysis has several limitations. The ascertainment of the endpoints in individual studies was inconsistent, which may have introduced confounders into the final analysis. In addition, heterogeneity could not be explored fully due to the unavailability of several essential factors. Finally, the inherent limitation in any meta-analysis, including publication bias, and individual data were not available.

\section{Conclusions}

Relative to standard BP control, IBP control was associated with a reduced risk of MACEs, MI, stroke, and albuminuria. However, IBP control has no significant effect on the risk of heart failure, all-cause mortality, cardiac death, non-cardiac death, ESRD, and retinopathy. Future investigations should clarify the correlation between cardiovascular and renal outcomes and the extent of $\mathrm{BP}$ reduction.

\section{Disclosure Statement}

The authors declare no conflicts of interest in this work.

\section{Funding Sources}

This study was funded by the Henan Scientific and Technological Research Projects (grant number 182102310166).

\section{References}

1 Mathers CD, Loncar D. Projections of global mortality and burden of disease from 2002 to 2030. PLoS Med. 2006 Nov;3(11):e442.

2 Roger VL, Go AS, Lloyd-Jones DM, Benjamin EJ, Berry JD, Borden WB, et al.; American Heart Association Statistics Committee and Stroke Statistics Subcommittee. Heart disease and stroke statistics—2012 update: a report from the American Heart Association. Circulation. 2012 Jan;125(1):e2-220.

3 Murray CJ, Atkinson C, Bhalla K, Birbeck G, Burstein R, Chou D, et al.; U.S. Burden of Disease Collaborators. The state of US health, 1990-2010: burden of diseases, injuries, and risk factors. JAMA. 2013 Aug;310(6):591-608.

4 Kochanek KD, Murphy SL, Xu J, Arias E. Mortality in the United States, 2013. NCHS Data Brief. 2014 Dec;(178): 1-8.

5 Lim SS, Vos T, Flaxman AD, Danaei G, Shibuya K, Adair-Rohani H, et al. A comparative risk assessment of burden of disease and injury attributable to 67 risk factors and risk factor clusters in 21 regions, 1990-2010: a systematic analysis for the Global Burden of Disease Study 2010. Lancet. 2012 Dec;380(9859):2224-60.

6 Law MR, Morris JK, Wald NJ. Use of blood pressure lowering drugs in the prevention of cardiovascular disease: meta-analysis of 147 randomised trials in the context of expectations from prospective epidemiological studies. BMJ. 2009 May;338(may19 1):b1665. 


\section{Kidney \\ Blood Pressure \\ Research}

\begin{tabular}{l|l}
\hline Kidney Blood Press Res 2019;44:384-395 \\
\hline DOI: 10.1159/000499009 & $\begin{array}{l}\text { @ 2019 The Author(s). Published by S. Karger AG, Basel } \\
\text { www.karger.com/kbr }\end{array}$ \\
\hline
\end{tabular}

$\mathrm{Li}$ and Li: Hypertension in the Prevention of Cardiovascular and Renal Outcomes

7 Staessen JA, Wang JG, Thijs L. Cardiovascular protection and blood pressure reduction: a meta-analysis. Lancet. 2001 Oct;358(9290):1305-15.

8 Turnbull F; Blood Pressure Lowering Treatment Trialists' Collaboration. Effects of different blood-pressurelowering regimens on major cardiovascular events: results of prospectively-designed overviews of randomised trials. Lancet. 2003 Nov;362(9395):1527-35.

9 Chobanian AV, Bakris GL, Black HR, Cushman WC, Green LA, Izzo JL Jr, et al.; National High Blood Pressure Education Program Coordinating Committee. The Seventh Report of the Joint National Committee on Prevention, Detection, Evaluation, and Treatment of High Blood Pressure: the JNC 7 report. JAMA. 2003 May; 289(19):2560-72.

10 European Society of Hypertension-European Society of Cardiology Guidelines Committee. 2003 European Society of Hypertension-European Society of Cardiology guidelines for the management of arterial hypertension. J Hypertens. 2003 Jun;21(6):1011-53.

11 Whitworth J, Whiteworth J, Isohwg WHO, A. Whitworth J. World Health Organization, International Society of Hypertension Writing Group. 2003 World Health Organization (WHO)/International Society of Hypertension (ISH) statement on management of hypertension. 2003.

12 Xie X, Atkins E, Lv J, Bennett A, Neal B, Ninomiya T, et al. Effects of intensive blood pressure lowering on cardiovascular and renal outcomes: updated systematic review and meta-analysis. Lancet. 2016 Jan;387(10017): 435-43.

13 Moher D, Liberati A, Tetzlaff J, Altman DG; PRISMA Group. Preferred reporting items for systematic reviews and meta-analyses: the PRISMA statement. PLoS Med. 2009 Jul;6(7):e1000097.

14 Jadad AR, Moore RA, Carroll D, Jenkinson C, Reynolds DJ, Gavaghan DJ, et al. Assessing the quality of reports of randomized clinical trials: is blinding necessary? Control Clin Trials. 1996 Feb;17(1):1-12.

15 DerSimonian R, Laird N. Meta-analysis in clinical trials. Control Clin Trials. 1986 Sep;7(3):177-88.

16 Ades AE, Lu G, Higgins JP. The interpretation of random-effects meta-analysis in decision models. Med Decis Making. 2005 Nov-Dec;25(6):646-54.

17 Deeks JJ, Higgins JP, Altman DG. Analysing Data and Undertaking Meta-Analyses. John Wiley \& Sons, Ltd; 2008. https://doi.org/10.1002/9780470712184.ch9.

18 Higgins JP, Thompson SG, Deeks JJ, Altman DG. Measuring inconsistency in meta-analyses. BMJ. 2003 Sep; 327(7414):557-60.

19 Tobias A. Assessing the influence of a single study in the meta-analysis estimate. Stata Tech Bull. 1999;8: 7526-9.

20 Egger M, Davey Smith G, Schneider M, Minder C. Bias in meta-analysis detected by a simple, graphical test. BMJ. 1997 Sep;315(7109):629-34.

21 Begg CB, Mazumdar M. Operating characteristics of a rank correlation test for publication bias. Biometrics. 1994 Dec;50(4):1088-101.

22 Toto RD, Mitchell HC, Smith RD, Lee HC, McIntire D, Pettinger WA. "Strict" blood pressure control and progression of renal disease in hypertensive nephrosclerosis. Kidney Int. 1995 Sep;48(3):851-9.

23 Hansson L, Zanchetti A, Carruthers SG, Dahlöf B, Elmfeldt D, Julius S, et al.; HOT Study Group. Effects of intensive blood-pressure lowering and low-dose aspirin in patients with hypertension: principal results of the Hypertension Optimal Treatment (HOT) randomised trial. Lancet. 1998 Jun;351(9118):1755-62.

24 UK Prospective Diabetes Study Group. Tight blood pressure control and risk of macrovascular and microvascular complications in type 2 diabetes: UKPDS 38. BMJ. 1998 Sep;317(7160):703-13.

25 Estacio RO, Jeffers BW, Gifford N, Schrier RW. Effect of blood pressure control on diabetic microvascular complications in patients with hypertension and type 2 diabetes. Diabetes Care. 2000 Apr;23 Suppl 2:B54-64.

26 Schrier RW, Estacio RO, Esler A, Mehler P. Effects of aggressive blood pressure control in normotensive type 2 diabetic patients on albuminuria, retinopathy and strokes. Kidney Int. 2002 Mar;61(3):1086-97.

27 Schrier R, McFann K, Johnson A, Chapman A, Edelstein C, Brosnahan G, et al. Cardiac and renal effects of standard versus rigorous blood pressure control in autosomal-dominant polycystic kidney disease: results of a seven-year prospective randomized study. J Am Soc Nephrol. 2002 Jul;13(7):1733-9.

28 Sarnak MJ, Greene T, Wang X, Beck G, Kusek JW, Collins AJ, et al. The effect of a lower target blood pressure on the progression of kidney disease: long-term follow-up of the modification of diet in renal disease study. Ann Intern Med. 2005 Mar;142(5):342-51.

29 Ruggenenti P, Perna A, Loriga G, Ganeva M, Ene-Iordache B, Turturro M, et al.; REIN-2 Study Group. Bloodpressure control for renoprotection in patients with non-diabetic chronic renal disease (REIN-2): multicentre, randomised controlled trial. Lancet. 2005 Mar;365(9463):939-46.

30 Estacio RO, Coll JR, Tran ZV, Schrier RW. Effect of intensive blood pressure control with valsartan on urinary albumin excretion in normotensive patients with type 2 diabetes. Am J Hypertens. 2006 Dec;19(12):1241-8.

31 JATOS Study Group. Principal results of the Japanese trial to assess optimal systolic blood pressure in elderly hypertensive patients (JATOS). Hypertens Res. 2008 Dec;31(12):2115-27.

32 Verdecchia P, Staessen JA, Angeli F, de Simone G, Achilli A, Ganau A, et al.; Cardio-Sis investigators. Usual versus tight control of systolic blood pressure in non-diabetic patients with hypertension (Cardio-Sis): an open-label randomised trial. Lancet. 2009 Aug;374(9689):525-33.

33 Reboldi G, Angeli F, de Simone G, Staessen JA, Verdecchia P; Cardio-Sis Investigators. Tight versus standard blood pressure control in patients with hypertension with and without cardiovascular disease. Hypertension. 2014 Mar;63(3):475-82. 
34 Wühl E, Trivelli A, Picca S, Litwin M, Peco-Antic A, Zurowska A, et al.; ESCAPE Trial Group. Strict blood-pressure control and progression of renal failure in children. N Engl J Med. 2009 Oct;361(17):1639-50.

35 Cushman WC, Evans GW, Byington RP, Goff DC Jr, Grimm RH Jr, Cutler JA, et al.; ACCORD Study Group. Effects of intensive blood-pressure control in type 2 diabetes mellitus. N Engl J Med. 2010 Apr;362(17):1575-85.

36 Ogihara T, Saruta T, Rakugi H, Matsuoka H, Shimamoto K, Shimada K, et al.; Valsartan in Elderly Isolated Systolic Hypertension Study Group. Target blood pressure for treatment of isolated systolic hypertension in the elderly: valsartan in elderly isolated systolic hypertension study. Hypertension. 2010 Aug;56(2):196-202.

37 Appel LJ, Wright JT Jr, Greene T, Agodoa LY, Astor BC, Bakris GL, et al.; AASK Collaborative Research Group. Intensive blood-pressure control in hypertensive chronic kidney disease. N Engl J Med. 2010 Sep;363(10): 918-29.

38 Asayama K, Ohkubo T, Metoki H, Obara T, Inoue R, Kikuya M, et al.; Hypertension Objective Treatment Based on Measurement by Electrical Devices of Blood Pressure (HOMED-BP). Cardiovascular outcomes in the first trial of antihypertensive therapy guided by self-measured home blood pressure. Hypertens Res. 2012 Nov; 35(11):1102-10.

39 Wei Y, Jin Z, Shen G, Zhao X, Yang W, Zhong Y, et al. Effects of intensive antihypertensive treatment on Chinese hypertensive patients older than 70 years. J Clin Hypertens (Greenwich). 2013 Jun;15(6):420-7.

40 Benavente OR, Coffey CS, Conwit R, Hart RG, McClure LA, Pearce LA, et al.; SPS3 Study Group. Blood-pressure targets in patients with recent lacunar stroke: the SPS3 randomised trial. Lancet. 2013 Aug;382(9891):50715.

41 Umemoto S, Ogihara T, Matsuzaki M, Rakugi H, Ohashi Y, Saruta T; Combination Therapy of Hypertension to Prevent Cardiovascular Events (COPE) Trial Group. Effects of calcium channel blocker benidipine-based combination therapy on target blood pressure control and cardiovascular outcome: a sub-analysis of the COPE trial. Hypertens Res. 2017 Apr;40(4):376-84.

42 Upadhya B, Rocco M, Lewis CE, Oparil S, Lovato LC, Cushman WC, et al.; SPRINT Research Group. Effect of Intensive Blood Pressure Treatment on Heart Failure Events in the Systolic Blood Pressure Reduction Intervention Trial. Circ Heart Fail. 2017 Apr;10(4):10.

43 Tsai WC, Wu HY, Peng YS, Yang JY, Chen HY, Chiu YL, et al. Association of Intensive Blood Pressure Control and Kidney Disease Progression in Nondiabetic Patients With Chronic Kidney Disease: A Systematic Review and Meta-analysis. JAMA Intern Med. 2017 Jun;177(6):792-9.

44 Weiss J, Freeman M, Low A, Fu R, Kerfoot A, Paynter R, et al. Benefits and Harms of Intensive Blood Pressure Treatment in Adults Aged 60 Years or Older: A Systematic Review and Meta-analysis. Ann Intern Med. 2017 Mar;166(6):419-29.

45 Reboldi G, Gentile G, Angeli F, Ambrosio G, Mancia G, Verdecchia P. Effects of intensive blood pressure reduction on myocardial infarction and stroke in diabetes: a meta-analysis in 73,913 patients. J Hypertens. 2011 Jul; 29(7):1253-69.

46 Casale PN, Devereux RB, Kligfield P, Eisenberg RR, Miller DH, Chaudhary BS, et al. Electrocardiographic detection of left ventricular hypertrophy: development and prospective validation of improved criteria. J Am Coll Cardiol. 1985 Sep;6(3):572-80. 